\title{
The Effect of 8-Azaguanine on the Inducible Oxidation of Guanine by Pseudomonas aeruginosa
}

\author{
By PATRICIA H. ClaRKE and PAULINE M. MEADOW \\ Biochemistry Department, University College, London, W.C.1
}

(Received 7 December 1965)

\begin{abstract}
SUMMARY
Pseudomonas aeruginosa NCTC 8203 was shown to metabolize guanine by deamination to xanthine, which was then oxidized to uric acid and further products. Guanine deaminase activity was present in non-induced bacteria but was 3-4 times greater in guanine-induced bacteria. Xanthine oxidase, and the uric acid oxidizing enzymes, were not found in bacteria grown in a minimal salts medium but were induced by adding guanine or xanthine to the culture medium towards the end of the growth period. When uric acid was added, only the uric acid oxidizing enzymes were induced. Enzyme induction also occurred when washed suspensions of the bacteria were incubated with guanine, xanthine or uric acid in Warburg flasks. 8-Azaguanine was deaminated more rapidly than guanine by non-induced bacteria and the rate was again greater with guanine-induced bacteria. 8-Azaguanine and 8-azaxanthine were not oxidized and did not induce the synthesis of deaminases or oxidases. 8-Azaguanine and 8-azaxanthine had no effect on the oxidation of guanine, xanthine or uric acid by fully induced bacteria. Equimolar concentrations of 8 -azaguanine inhibited adaptation to the oxidation of guanine, xanthine and uric acid when added before the substrates. 8-Azaxanthine, under the same conditions, delayed adaptation to guanine and xanthine oxidation, and completely inhibited adaptation to uric acid. Mutant strains were isolated which were resistant to $10 \mathrm{~mm}$ 8-azaguanine and 5 mM-8-azaxanthine which completely inhibited growth of the parent strain. Another class of mutants was isolated resistant to 8 -azaguanine and not resistant to 8-azaxanthine. Both classes of mutants were indistinguishable from the parent strain in their susceptibility to 8 -azaguanine and 8-azaxanthine inhibition of adaptation to purine oxidation.
\end{abstract}

\section{INTRODUCTION}

The purine analogue 8 -azaguanine is readily incorporated into the ribonucleic acid of some bacterial species (Smith \& Matthews, 1957; Mandel \& Markham, 1958), and prevents the synthesis of some inducible enzymes when added at the same time as the inducer (Creaser, 1956). We found that 8-azaguanine appeared to inhibit to some extent the synthesis by Pseudomonas aeruginosa of inducible permeases for some carbon compounds but not for others (Clarke \& Meadow, 1959). We found that washed suspensions of the bacteria grown in the absence of succinate, which had decreased succinate permease activity, had an increased oxygen uptake with succinate as substrate in the presence of 8-azaguanine. One explanation for these results, was that 8 -azaguanine was deaminated by the bacteria, thereby increasing the nitrogen compounds available for synthesizing succinate permease and oxidase. Bergmann, Ungar-Waron \& Kwietny-Govrin (1964) have since shown 
that 8 -azaguanine is slowly converted to 8 -azaxanthine by $\boldsymbol{P}$. aeruginosa growing in minimal medium in the presence of 8 -azaguanine. Pseudomonads are known to form inducible enzymes which enable them to metabolize various purines (Bachrach, 1957; Dikstein, Bergmann \& Henis, 1957). In the present work we have followed the deamination and oxidation of guanine by $P$. aeruginosa and examined the effects of 8-azaguanine and 8-azaxanthine on guanine metabolism by induced and non-induced bacteria.

\section{METHODS}

Organism. The strain used was Pseudomonas aeruginosa NCTC 8203 maintained as described by Clarke \& Meadow (1959).

Media. The bacteria were grown in a minimal salts medium with $20 \mathrm{~mm}$-succinate as carbon source (Brammar \& Clarke, 1964). The washed suspensions were prepared from bacteria incubated for $16-18 \mathrm{hr}$ in $100 \mathrm{ml}$. batch cultures in 1 l. flasks shaken at $37^{\circ}$ on a mechanical shaker. To obtain induced cultures, bacteria were grown for about $16 \mathrm{hr}$ to an extinction reading at $670 \mathrm{~m} \mu$ of about $0 \cdot 9-1 \cdot 2$ (equiv. 0.5-0.6 $\mathrm{mg}$. dry wt./ml.). Measurements of extinction were made with a Unicam SP 600 spectrophotometer (Unicam Instruments Ltd.). The appropriate purine was then added to give a final concentration of $2 \mathrm{~mm}$ and the incubation continued for a further $2 \mathrm{hr}$. The cultures were harvested by centrifugation and resuspended in $25 \mathrm{ml} .100 \mathrm{~mm}$ -

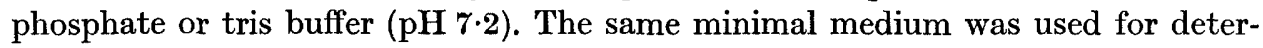
mination of the growth-inhibitory concentrations of 8-azaguanine and 8-azaxanthine, with $1 \cdot 2 \%(\mathrm{w} / \mathrm{v})$ New Zealand agar added for plate cultures.

Enzyme activities. Oxygen uptake was measured by the conventional Warburg technique at $37^{\circ}$ with air as the gas phase and $0.2 \mathrm{ml} .40 \%(\mathrm{w} / \mathrm{v}) \mathrm{KOH}$ in the centre well. The main compartment of the Warburg vessel contained $1 \mathrm{ml}$. cell-free extract (equiv. $5 \mathrm{mg}$. dry wt. original bacterial suspension $/ \mathrm{ml}$.) or $1 \mathrm{ml}$. bacterial suspension (equiv. $2 \mathrm{mg}$. dry wt. bacteria/ml.). Phosphate buffer $100 \mathrm{~mm}$ (pH 7.2) was used unless stated otherwise, to give a final volume of $\mathbf{3 . 0} \mathrm{ml}$. Substrates or inhibitors were added from the side arm after equilibration for $20 \mathrm{~min}$. Double side-arm flasks were used when required.

Deaminase activity was measured by estimating the ammonia released during aerobic or anaerobic incubation of cell preparations with the substrates, using the Conway microdiffusion technique for ammonia estimation followed by titration with $20 \mathrm{~mm}-\mathrm{HCl}$ (Conway, 1957).

Cell-free extracts. Washed suspensions of bacteria, concentrated 10-fold in phosphate buffer, were disrupted using a bacterial press modified from that described by Milner, Lawrence \& French (1950). Unbroken bacteria and debris were removed by centrifugation at $10,000 \mathrm{~g}$ for $20 \mathrm{~min}$.

Viable counts. Samples $(0.1 \mathrm{ml}$.) of a suitable dilution of bacteria were spread on agar plates. Lemco agar (Clarke \& Meadow, 1959) was used for counting the total number of viable bacteria and minimal agar +8 -azaguanine or 8 -azaxanthine for counting the number of resistant bacteria.

Resistance tests. Minimal medium(5 ml.) containing 8-azaguanine or 8-azaxanthine was inoculated with about $10^{4}$ bacteria and growth estimated by visual examination after $24 \mathrm{hr}$ at $37^{\circ}$. Plate cultures were inoculated with 100-200 bacteria and the number and size of colonies determined after $24 \mathrm{hr}$ at $37^{\circ}$. 
Paper electrophoresis. Purines were separated by paper electrophoresis in 50 mmsodium borate buffer $(\mathrm{pH} 9 \cdot 2)$ and also in formic acid $(1 \cdot 5 \mathrm{M})+$ acetic acid $(2 \mathrm{M})$ $(1+1$ by vol.) buffer ( $\mathrm{pH} \mathrm{2}$ ). Solutions were applied to Whatman no. 1 paper and subjected to $2 \cdot 6 \mathrm{KV}(80 \mathrm{~mA})$ for $30 \mathrm{~min}$. After drying, the purines were detected by their ultraviolet absorption and identified by comparison with authentic compounds.

Chemicals. Guanine, xanthine, hypoxanthine, uric acid, 8-azaguanine and 8azaxanthine were obtained from L. Light and Co. Ltd. (Colnbrook, Bucks). These compounds are, except for uric acid, only very slightly soluble in water. The stock suspensions were prepared in a finely divided state by grinding the solid and heating it in a suitable volume of boiling water for $10 \mathrm{~min}$.

\section{RESULTS}

\section{Oxidation of guanine}

Washed suspensions of Pseudomonas aeruginosa grown in the minimal medium were not able to oxidize guanine until they had been incubated with the substrate for some time. Chloramphenicol inhibited this adaptation but had no effect on the oxidation of guanine by fully induced bacteria (Fig. 1 $a, b$ ). The time taken for non-induced bacteria to reach a rapid rate of guanine oxidation could be varied by altering the conditions of the experiment. Bacteria suspended in phosphate buffer adapted more rapidly than those suspended in tris buffer. The carbon pool also affected the duration of the lag period and in some experiments with washed

\section{Table 1. Deamination and oxidation of guanine by Pseudomonas aeruginosa NCTC 8203}

Values for $\mathbf{2 4 0}$ min. incubation in air in Warburg flasks, corrected for endogenous $\mathrm{O}_{2}$ uptake $102 \mu 1$.

$\begin{array}{cccccc}\begin{array}{c}\text { Guanine } \\ \mu \text { mole/flask }\end{array} & \begin{array}{c}\mathrm{O}_{2} \\ \text { uptake } \\ (\mu \mathrm{l} .)\end{array} & \begin{array}{c}\mathrm{O}_{2} \\ (\mu \mathrm{mole})\end{array} & \begin{array}{c}\mathrm{NH}_{3} \\ (\mu \mathrm{mole})\end{array} & \mathrm{O}_{2} \text { : Guanine } & \mathrm{NH}_{3} \text { : Guanine } \\ 4 & 96 & 4 \cdot 3 & - & 1 \cdot 08 & - \\ & 102 & 4 \cdot 5 & - & 1 \cdot 14 & - \\ 8 & 205 & 9 \cdot 1 & 8 \cdot 7 & 1 \cdot 14 & 1 \cdot 09 \\ & 191 & 8 \cdot 5 & 8 \cdot 1 & 1 \cdot 06 & 1 \cdot 01 \\ 12 & 187 & 8 \cdot 3 & - & 1 \cdot 04 & - \\ & 294 & 13 \cdot 1 & 11 \cdot 9 & 1 \cdot 09 & 0.98 \\ & 284 & 12 \cdot 7 & 12 \cdot 0 & 1 \cdot 06 & 1 \cdot 00 \\ & 290 & 12.9 & 12 \cdot 0 & 1 \cdot 08 & 1.00\end{array}$

carbon-starved bacteria grown in minimal medium containing $10 \mathrm{~mm}$-succinate, no adaptation to guanine oxidation was detected. The bacterial culture had a low endogenous oxidation rate after 16-18 hr growth in the standard minimal medium and adaptation to guanine oxidation could also be measured with samples of unwashed bacteria taken directly from the culture medium. There was a wide variation in the time taken for complete adaptation to guanine by suspensions prepared under these different conditions. Washed suspensions prepared in phosphate buffer from bacteria grown under the standard conditions became fully adapted in 60-90 $\mathrm{min}$. Washed suspensions in tris buffer and washed suspensions of 
carbon-starved bacteria were found to take $120 \mathrm{~min}$. or longer to become fully adapted.

Figure $1 b$ gives the results of an experiment in which the bacteria had become fully induced during the $2-\mathrm{hr}$ growth period in the presence of guanine. In other experiments the adaptation to guanine was not completed during this time so that bacteria harvested after $2 \mathrm{hr}$ continued to adapt to guanine in the Warburg flasks. Incomplete adaptation to guanine oxidation was shown by non-linear oxygen uptake and partial inhibition by chloramphenicol. Cultures which had stopped growing because of exhaustion of the carbon source, and cultures which were well into the stationary phase, did not adapt to guanine oxidation as well or as rapidly as cultures which had not quite reached maximum growth.

It seemed likely that guanine was being metabolized by deamination to xanthine followed by the oxidation of xanthine to uric acid and other products. Guanine deaminase activity was present in non-induced bacteria and the activity was

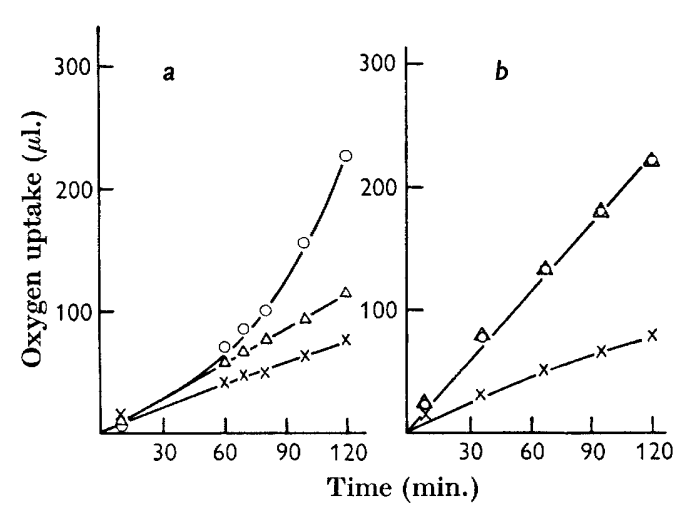

Fig. $1(a$ and $b)$

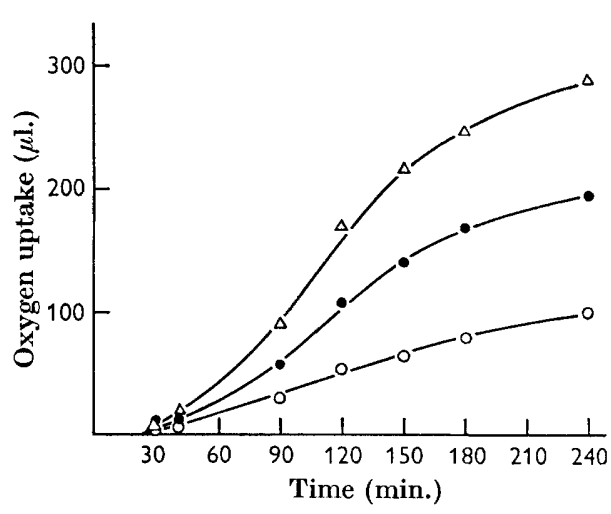

Fig. 2

Fig. $1 a, b$. Effect of chloramphenicol on guanine oxidation by washed bacterial suspensions in phosphate buffer of $(a)$ non-induced, $(b)$ guanine-induced cultures of Pseudomonas aeruginosa NCTC 8203 equiv. $2 \mathrm{mg}$. dry wt. bacteria/flask. $100 \mathrm{~mm}$-phosphate buffer (pH 7.2). Total vol. $3 \mathrm{ml}$. $\bigcirc-O$, guanine (10 mM); $\triangle-\triangle$, guanine (10 mM) + chloramphenicol (60 $\mu \mathrm{g} . / \mathrm{ml}$.); $\times-\times$, endogenous.

Fig. 2. Oxygen uptake by washed suspensions of Pseudomonas aeruginosa NCTC 8203 resuspended in $100 \mathrm{~mm}$-tris buffer (pH 7.2). Equiv. $2 \mathrm{mg}$. dry wt. bacteria/flask. Total vol. $3 \mathrm{ml}$. $\bigcirc-\mathrm{O}, 4 \mu \mathrm{mole}$ guanine; $-0,8 \mu$ mole guanine; $\triangle-\Delta, 12 \mu \mathrm{mole}$ guanine. Values for endogenous oxygen uptake have been subtracted.

about $\mathbf{2 5 - 3 0} \%$ of that of guanine-induced bacteria. This is considered in more detail in connection with the metabolism of 8-azaguanine (see Fig. 5).

The extent of deamination and oxidation of guanine was compared at low substrate concentrations $(4,8,12 \mu$ mole/flask). Table 1 and Fig. 2 give the results of an experiment with non-induced bacteria resuspended in tris buffer $(\mathrm{pH} \mathrm{7 \cdot 2)}$. The endogenous oxygen uptake (102 $\mu \mathrm{l} . / 240 \mathrm{~min}$.) has been subtracted. Endogenous ammonia production was negligible. The lag period before any guanine oxidation was detected under these conditions was about $30 \mathrm{~min}$., and after $240 \mathrm{~min}$. the rate of oxygen uptake in the flasks containing guanine had decreased almost to the endogenous rate. The $\mathrm{NH}_{3}$ : guanine ratio after this time was $1: 1$ so that it could be 
concluded that the guanine was completely deaminated by the end of the experimental period. After $\mathbf{2 4 0}$ min. the oxygen uptake was very slightly greater than could be accounted for by the oxidation of xanthine to uric acid.

In another experiment the ammonia production was compared with the oxygen uptake under conditions in which the substrate was present in excess $(40 \mu$ mole/ flask) by setting up several Warburg flasks in parallel to determine oxygen uptake, and removing single flasks at intervals for ammonia determinations. Up to about $180 \mathrm{~min}$. the oxygen uptake was approximately equivalent to the ammonia released. This experiment was made with non-induced bacteria to avoid any substrate being carried over from the growth medium; it was therefore comparable to the conditions of the experiment in Fig. $1 a$. When washed suspensions of non-induced bacteria were incubated with guanine for longer periods the oxygen uptake reached values of $\mathrm{O}_{2}$ :guanine of over 3:1, which can only be accounted for by further oxidation of uric acid.

It seemed possible that under some conditions the guanine was being deaminated more rapidly than xanthine was being oxidized, particularly since the bacteria grown under all conditions had some deaminase activity but, as we found later, only the guanine- (or xanthine-) induced cultures had xanthine oxidase activity. Flask contents from an experiment done in the same way as that shown in Fig. $1 a$ were analysed for purines after incubation for $6 \mathrm{hr}$. The bacteria were separated by centrifugation and extracted by boiling for $5 \mathrm{~min}$. with $0.5 \mathrm{ml} . \mathrm{Na}_{2} \mathrm{CO}_{3}(1 \%, \mathrm{w} / \mathrm{v})$. These extracts, and the supernatant fluid from the flask contents, were subjected to paper electrophoresis as described in Methods. Guanine was the only purine detected in the supernatant fluid, but extracts from bacteria which had been actively metabolizing guanine contained guanine and xanthine in approximately equal amounts. The method did not allow for the detection of uric acid. It was concluded that guanine was being deaminated more rapidly than the xanthine was being oxidized, and that even under the conditions when there was an apparent molar correspondence of ammonia release and oxygen uptake, at least a fraction of the uric acid produced was being further oxidized.

\section{Adaptation to guanine, xanthine and uric acid}

Non-induced cultures were able to adapt to the oxidation of xanthine and uric acid after incubation for some time with these substrates in Warburg flasks or in culture medium. The pattern of enzyme induction of bacteria induced with guanine, xanthine and uric acid, respectively, was examined. In a series of experiments $16 \mathrm{hr}$ cultures were incubated for a further $2 \mathrm{hr}$ with and without purine inducers. After this time the oxygen uptake of the washed suspensions was measured with these three compounds as separate substrates. Cultures induced with guanine or xanthine oxidized guanine, xanthine or uric acid without an appreciable lag (Fig. 3a,b). Those induced with uric acid were able to oxidize immediately only uric acid (Fig. $3 c$ ). As found previously with guanine adaptation, there was considerable variation in the adaptation to uric acid of bacteria grown under different conditions. Bacteria which had been in the stationary phase for some time were very poor at adapting to uric acid. Occasional batches of bacteria gave a higher rate of uric acid oxidation than that shown in Fig. $3 c$, but in no case did a uric acid induced culture show any 
concomitant adaptation to guanine or xanthine. Figure $\mathbf{3} d$ shows that washed suspensions of bacteria grown under these conditions without added purine inducers were induced to form the oxidative enzymes only after 60-90 min. of incubation. These results suggest that during adaptation to guanine, xanthine oxidase is induced by xanthine (and possibly guanine) and that the uric acid formed then induces the formation of enzymes for its own oxidation.
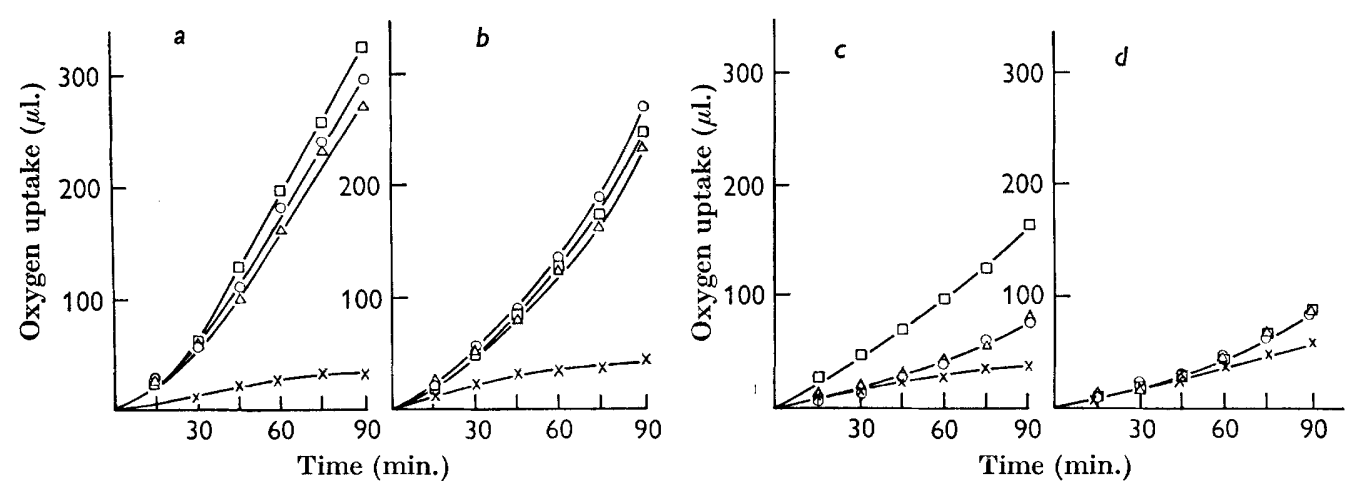

Fig. 3. Oxidation of guanine, xanthine and uric by washed suspensions of Pseudomonas aeruginosa NCTC 8203 in phosphate buffer. (a) guanine-induced; $(b)$ xanthine-induced; $(c)$ uric acid-induced; $(d)$ non-induced. 100 mM-phosphate buffer (pH 7·2). Equiv. 2 mg. dry wt. bacteria/flask. Total vol. $3 \mathrm{ml}$. $\bigcirc-\bigcirc$, guanine; $\triangle-\triangle$, xanthine; $\square-\square$, uric acid; $x-x$, endogenous. Substrates $10 \mathrm{~mm}$.

\section{Cell-free extracts}

The lag period before the oxidation of guanine, xanthine or uric acid by washed suspensions of non-induced bacteria might be due to the synthesis of deaminating enzymes or oxidative enzymes, or to the synthesis of permeases needed to transport the substrates into the cell. Cell-free extracts were therefore prepared and their oxidative abilities compared with those of whole bacteria (Fig. $4 a, b$ ). Chloramphenicol was added to all flasks to prevent adaptation during the experiment. Cell-free extracts from guanine-induced cultures oxidized guanine and xanthine at comparable rates though much more slowly than did the whole bacteria from which they were derived. Uric acid was not oxidized by these extracts (Fig. $4 b$ ). None of the extracts from non-induced cultures oxidized guanine, xanthine or uric acid. Induction by guanine and xanthine must therefore involve the synthesis of xanthine oxidase, though it may also include the synthesis of permeases for guanine and xanthine.

\section{Metabolism of 8-azaguanine}

Bergmann et al. (1964) found that after 24-hr growth of cultures of Pseudomonas aeruginosa in a minimal medium containing originally 8 -azaguanine $100 \mu \mathrm{g} . / \mathrm{ml}$. they could detect only 8 -azaxanthine in the medium and concluded that the 8 -azaguanine had been slowly deaminated. We found that non-induced cultures of our strain of $\boldsymbol{P}$. aeruginosa which were able to deaminate guanine were also able to deaminate 8-azaguanine. 8-Azaguanine was more rapidly deaminated than guanine by both induced and non-induced cultures incubated under anaerobic conditions 
(Fig. 5). Non-induced cultures invariably possessed guanine deaminase activity, but the rate of deamination was very low so that rate-measurements were less accurate than those for induced cultures or for 8-azaguanine deaminase activity of induced and non-induced cultures. Increase in guanine deaminase activity was always accompanied by increase in 8-azaguanine deaminase activity, and it seemed reasonable to conclude that the same enzyme was responsible for the deamination of

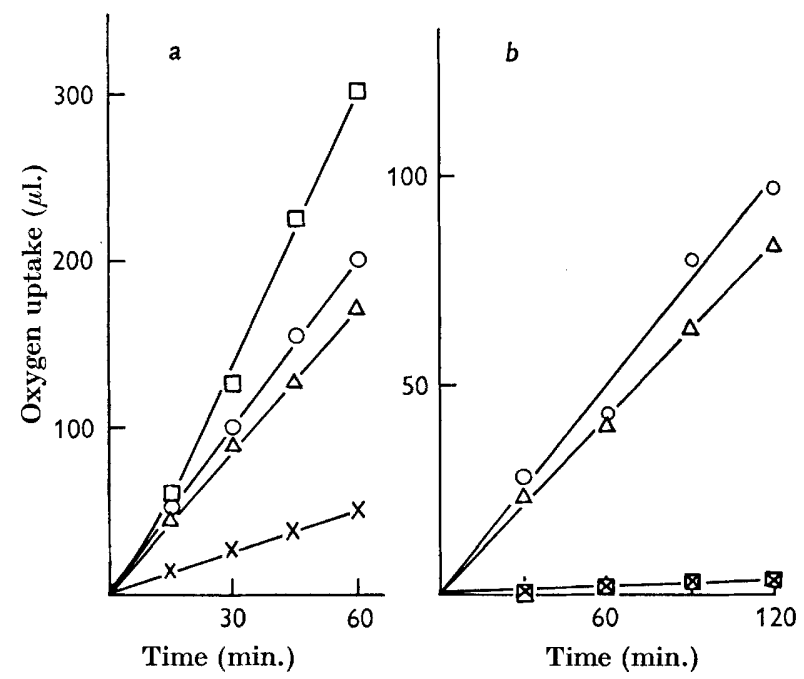

Fig. $4(a$ and $b)$

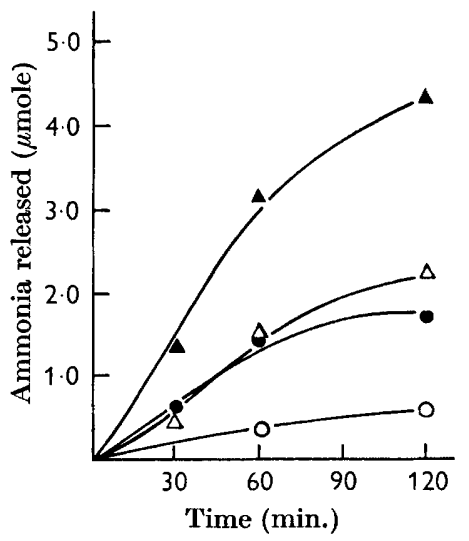

Fig. 5

Fig. 4. Oxidation of guanine, xanthine and uric acid in phosphate buffer by washed suspensions and cell-free extracts of guanine-adapted Pseudomonas aeruginosa NCTc 8203. (a) whole organisms equiv. $2 \mathrm{mg}$. dry wt./flask; $(b)$ cell-free extracts $1 \mathrm{ml}$. extract from equiv. $5 \mathrm{mg}$. dry wt. bacteria/flask. $\bigcirc-\bigcirc$, guanine; $\triangle-\Delta$, xanthine; $\square-\square$, uric acid; $x-x$, endogenous. Substrates $10 \mathrm{~mm}$; chloramphenicol $60 \mu \mathrm{g} . / \mathrm{ml}$. present in all flasks. $100 \mathrm{~mm}$-phosphate buffer (pH 7·2). Total vol. $3 \mathrm{ml}$.

Fig. 5. Anaerobic deamination of guanine and 8-azaguanine by washed suspensions of Pseudomonas aeruginosa NCTC 8203. Unadapted bacteria: $O-O$, guanine; $\triangle-\triangle$, 8-azaguanine. Guanine adapted bacteria: $--O$, guanine; $\Delta-\Delta, 8$-azaguanine. Experiment done in $\mathrm{N}_{2}$ in Warburg flasks. $2.0 \mathrm{ml}$. bacterial suspension in $100 \mathrm{~mm}$-tris buffer (pH 7.2); $10 \mathrm{~mm}$ substrates.

both purines. The enzyme is thus comparable with the rat liver guanase studied by Roush \& Norris (1950). When washed suspensions of non-induced cultures were incubated with guanine in air for $2 \mathrm{hr}$ the deaminase activity followed a typical induction curve due to increased synthesis of enzyme. This induction was prevented by chloramphenicol. The deaminase activity of non-induced bacteria incubated with 8-azaguanine was the same for washed suspensions incubated $(a)$ aerobically, $(b)$ aerobically in the presence of chloramphenicol, or $(c)$ anaerobically. It appears therefore that 8-azaguanine does not act as an inducer for the deaminase, although it is a substrate of the enzyme.

\section{Effect of 8-azaguanine and 8-azaxanthine on oxidation and adaptation}

Since 8-azaguanine was deaminated by Pseudomonas aeruginosa NCTC 8203, it seemed possible that the 8 -azaxanthine so formed might be oxidized by enzymes 
analogous to, or identical with, those which oxidized xanthine. Washed suspensions of non-induced bacteria were therefore incubated with $10 \mathrm{~mm}$-8-azaguanine or $10 \mathrm{~mm}$-8-azaxanthine and the oxygen uptake followed manometrically. No increase in oxygen uptake over the endogenous rate was detected even after incubation for $6 \mathrm{hr}$. Organisms induced by adding guanine, xanthine, uric acid, 8-azaguanine or 8 -azaxanthine to the culture medium $2 \mathrm{hr}$ before harvesting, were also unable to oxidize 8-azaguanine or 8-azaxanthine. These two analogues were not therefore oxidized by the enzymes which metabolized guanine and xanthine, and there was no comparable induction of enzymes which oxidized 8-azaguanine or 8-azaxanthine.
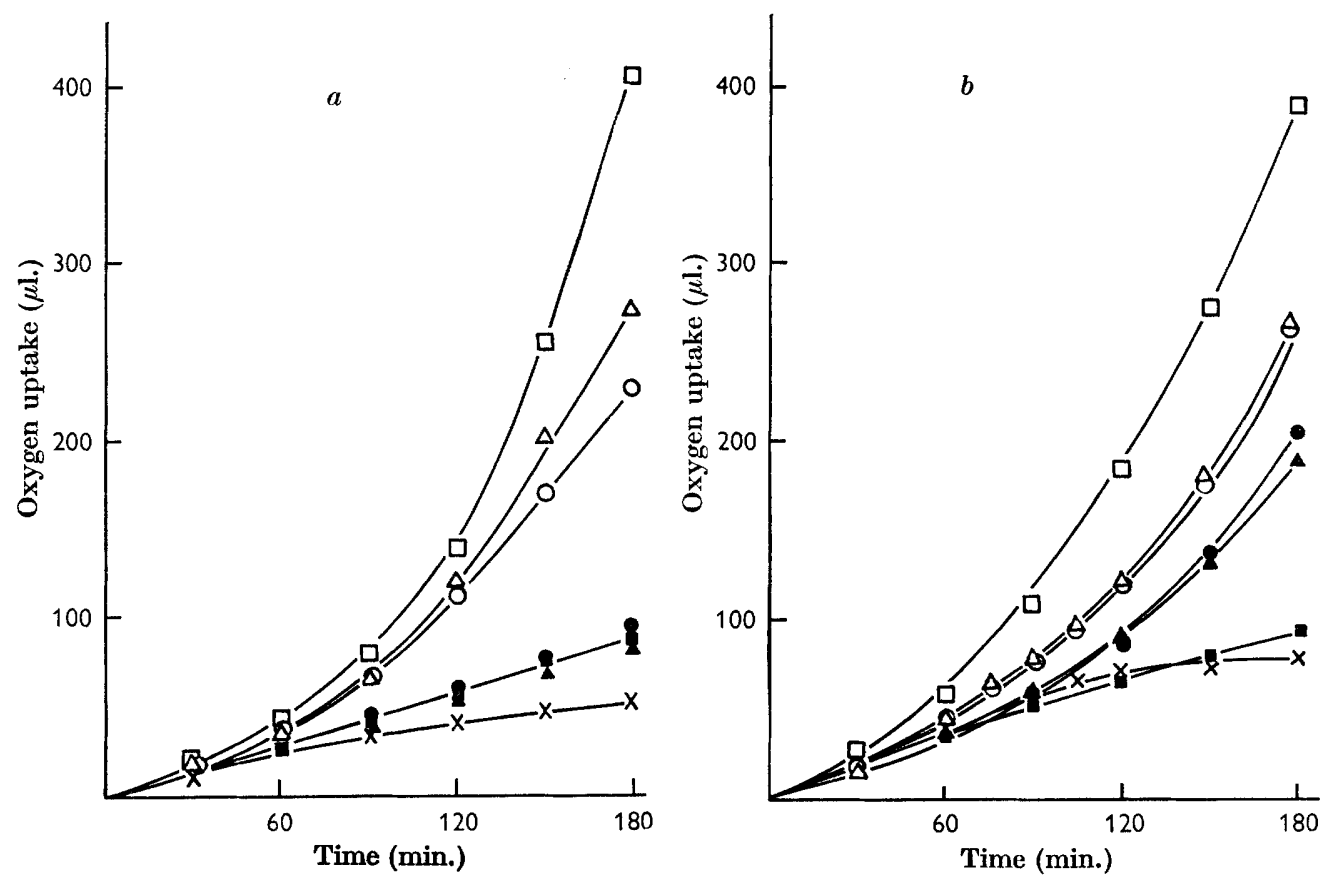

Fig. 6. Effect of $(a)$ 8-azaguanine and $(b)$ 8-azaxanthine on adaptation of washed suspensions of Pseudomonas aeruginosa NCTC 8203 in phosphate buffer. $100 \mathrm{~mm}$-phosphate buffer (pH 7.2). Substrates and analogues $10 \mathrm{~mm}$. Equiv. $2 \mathrm{mg}$. dry wt. bacteria/flask. Total vol. $3 \mathrm{ml}$. $\bigcirc-\bigcirc$, guanine; -0, guanine + 8-azaguanine (or 8-azaxanthine); $\triangle-\triangle$, xanthine; $\Delta-\Delta$, xanthine + 8-azaguanine (or 8-azaxanthine); $\square-\square$, uric acid; -1, uric acid +8 -azaguanine (or 8-azaxanthine); $\times-\times$, endogenous.

The oxygen uptake of washed suspensions which actively metabolized guanine, xanthine and uric acid was unaffected by the addition of 8-azaguanine or 8-azaxanthine even in 100-fold excess. One explanation for this lack of inhibition might be that under the experimental conditions the aza-analogues do not enter the organism. However, the oxidation of guanine and xanthine by cell-free extracts was not affected by 8-azaguanine or 8-azaxanthine. These two compounds do not therefore act as inhibitors of xanthine oxidase or any of the enzymes which oxidize uric acid.

Experiments were made to determine the effect of 8-azaguanine and 8-azaxanthine on the induction process. Non-induced cultures were incubated in the Warburg 
apparatus with 10 mm-guanine, equimolar 8-azaguanine being added at various times both before and during induction. A normal induction curve for guanine was obtained in all flasks except those in which the 8-azaguanine had been added before the guanine. Simultaneous addition of 8 -azaguanine and guanine delayed induction slightly, but the final oxygen uptake was unchanged. The insolubility of the purines and their aza-analogues made it difficult to determine the absolute concentrations required for inhibition but, by decreasing the guanine concentration, it was possible to show that induction was inhibited only when 8 -azaguanine was at least equimolar with guanine. Figure $6 a$ shows the effect of 8 -azaguanine, pre-incubated with the organisms for $20 \mathrm{~min}$. before the addition of the other purine, on the adaptation to guanine, xanthine and uric acid. All three induction processes were inhibited by 8-azaguanine under these conditions. Adaptation to uric acid was less susceptible to 8-azaguanine than was adaptation to the other two purines and under some conditions, for example, in tris buffer or in growth medium, adaptation to uric acid was not inhibited at all by 8 -azaguanine.

The incubation processes were affected quite differently by 8-azaxanthine under the same conditions (Fig. $6 b$ ). Adaptation to guanine and xanthine oxidation was delayed, but not inhibited, by equimolar 8 -azaxanthine, while adaptation to uric acid was completely prevented. All three induction processes were considerably less susceptible to 8-azaxanthine than to 8-azaguanine, and in tris buffer adaptation to all three purines proceeded normally even after pre-incubation with equimolar 8-azaxanthine.

\section{Growth and growth inhibition}

For this strain (NCTC 8203) of Pseudomonas aeruginosa guanine is a poor carbon source but an excellent nitrogen source. It was thought that if 8-azaguanine was so readily deaminated it might be also utilized as a nitrogen source. This proved to be the case and although there was no growth at higher concentrations, good growth of plate cultures was obtained with a medium containing $20 \mathrm{~mm}$-succinate as carbon source $+4 \mathrm{~mm}$-8-azaguanine as nitrogen source. No growth was obtained without an additional carbon source. This result was somewhat surprising since both 8 -azaguanine and 8-azaxanthine are known as growth inhibitors. In a minimal salts medium $50 \%$ inhibition of growth was obtained with $3 \mathrm{~mm}$-8-azaguanine in liquid medium and with $8 \mathrm{~mm}$ in a solid medium. 8-Azaxanthine was growth inhibitory at much lower concentrations than 8 -azaguanine; in minimal salts medium $50 \%$ inhibition of growth was obtained with $100 \mu \mathrm{M}-8$-azaxanthine in both liquid and solid media. Growth inhibition was annulled by adding excess guanine or xanthine.

\section{Isolation of resistant strains}

We were able to isolate resistant mutants of Pseudomonas aeruginosa NCTC 8203 by adding 8 -azaguanine to the medium and using a heavy inoculum. Four flasks were set up containing $100 \mathrm{ml}$. minimal medium and inoculated with about $10^{10}$ bacteria. The results are given in Table 2 . There was no growth lag for the control culture (A) but with 5 mm-8-azaguanine (D) the lag was $2 \mathrm{hr}$ and with $10 \mathrm{~mm}$ (C) it was $12-14 \mathrm{hr}$. It was impossible to make accurate growth measurements for the flask with $20 \mathrm{mM}$-8-azaguanine (B) since there was some undissolved 8-azaguanine 
in suspension; but after $24 \mathrm{hr}$ the growth was comparable with that in the other flasks.

After $26 \mathrm{hr}$, samples were taken to determine the total viable count of the cultures and the numbers of resistant bacteria. The total count was similar for all four cultures. No resistant bacteria were found on the plates inoculated from the control flask, but a high proportion of the bacteria from flasks $\mathrm{B}$ and $\mathrm{C}$ were resistant to $10 \mathrm{~mm}$-8-azaguanine and to $\mathrm{mm}$-8-azaxanthine. Although no resistant colonies

Table 2. Isolation of strains of Pseudomonas aeruginosa NCTC 8203 resistant to 8-azaguanine and 8-azaxanthine

\begin{tabular}{|c|c|c|c|c|}
\hline & \multicolumn{4}{|c|}{ Flask } \\
\hline & $\mathbf{A}$ & $\mathbf{B}$ & C & $\mathbf{D}$ \\
\hline Concentration of 8-azaguanine added to medium: & 0 & $20 \mathrm{mM}$ & $10 \mathrm{~mm}$ & $5 \mathrm{~mm}$ \\
\hline Duration of growth lag (hr) & $\mathbf{0}$ & $(0)$ & $12-14$ & 2 \\
\hline \multicolumn{5}{|l|}{ Viable count after $26 \mathrm{hr}\left(\text { bacteria } / \mathrm{ml} . \times 10^{-7}\right)^{*}$} \\
\hline Lemco agar & 189 & 114 & 195 & 132 \\
\hline Minimal agar + 10 mu-8-azaguanine & 0 & 131 & 85 & 0 \\
\hline Minimal agar + mm-8-azaxanthine & 0 & 68 & 30 & 0 \\
\hline 8 -azaguanine resistance $\dagger 10 \mathrm{~mm}$ & 0 & $++t$ & $+++t$ & 0 \\
\hline $1 \mathrm{~mm}$ & + & +++ & $++t+$ & + \\
\hline 8 -azaxanthine resistance $\dagger 10 \mathrm{~mm}$ & 0 & + & +++ & 0 \\
\hline $1 \mathrm{~mm}$ & 0 & ++++ & +++ & 0 \\
\hline $0.1 \mathrm{~mm}$ & + & $+t+$ & $++t+$ & $++t$ \\
\hline
\end{tabular}

(0) Could not be determined; * Culture diluted $\times 10^{6}, 0 \cdot 1 \mathrm{ml}$. spread on plate; $\dagger$ Growth after $24 \mathrm{hr}$ in liquid media.

Table 3. Growth of resistant mutants of Pseudomonas aeruginosa NCTC 8203

\begin{abstract}
AG mutants were obtained from single colonies on minimal medium +8 -azaguanine and $\mathrm{Ax}$ mutants from minimal medium +8 -azaxanthine. For the viable counts cultures were grown for $18 \mathrm{hr}$ in minimal medium, diluted $10^{6}$, and $0.1 \mathrm{ml}$. spread on the counting medium.
\end{abstract}

Counting medium

$\begin{array}{ccc}\text { Minimal agar }+ & \text { Minimal agar }+ \\ \text { Lemco agar } & \text { 8-azaguanine }(10 \mathrm{~mm}) & \text { 8-azaxanthine }(5 \mathrm{~mm})\end{array}$

Mutant
AG 1
AG 2
AG 4
AG 6
AX 1
AX 3

Viable count (bacteria $\times 10^{-7} / \mathrm{ml}$.)

\begin{tabular}{rrr}
\hline 188 & 184 & 181 \\
62 & 66 & 62 \\
64 & 56 & 0 \\
270 & 252 & 0 \\
72 & 96 & 99 \\
70 & 79 & 83
\end{tabular}

were found on the plates inoculated with about $10^{2}$ bacteria from flask $\mathrm{D}, 2-3$ resistant colonies occurred on plates inoculated with $10^{4}$ bacteria from this flask, although again none were found on plates inoculated with the same number of bacteria from the control culture. It appeared that resistance to 8-azaguanine or 8-azaxanthine occurred very readily and that growth under these conditions selected resistant mutants. Suitable dilutions of the flask cultures were made for resistance tests in liquid medium; these confirmed that flasks $\mathbf{B}$ and $\mathbf{C}$ contained a high proportion of resistant bacteria. Several colonies were picked from the plates containing 8-azaguanine (AG strains) or 8-azaxanthine (AX strains) to test 
whether a single factor was involved in resistance to both purine analogues. The single-colony isolates were inoculated into minimal medium and grown overnight. The cultures were then plated on Lemco agar and on minimal agar containing 8 -azaguanine or 8-azaxanthine. It can be seen from Table 3 that there were two classes of mutants isolated from the 8-azaguanine plates. Mutants AG 1 and AG 2 grew equally well in the presence of concentrations of the two purine analogues which would inhibit the growth of the parent culture. Mutants AG 4 and AG 6 were resistant to 8-azaguanine but were not resistant to 8-azaxanthine. All the mutants isolated from plates containing 8-azaxanthine were resistant to both purine analogues; mutants $\mathrm{AX} 1$ and $\mathrm{Ax} 3$ are typical cultures of this type. Representative mutants of each class (AG $1, A G 4, A X 1)$ were tested with guanine and 8-azaguanine in the Warburg apparatus. They behaved in the same way as wild-type organisms, adaptation to guanine oxidation being inhibited by pre-incubation with equimolar 8-azaguanine.

\section{DISCUSSION}

The experiments reported here are consistent with the view that the metabolism of guanine by Pseudomonas aeruginosa NCTC 8203 occurs by the same mechanism as in other strains of this species. Guanine is first deaminated to xanthine which is then oxidized to uric acid before breakdown of the purine ring system (Bachrach, 1957; Dikstein et al. 1957). The observed oxygen uptake in the presence of guanine results from its deamination to xanthine which is subsequently oxidized by xanthine oxidase and uric acid-oxidizing enzymes. In this organism some of the purinemetabolizing enzymes are inducible. Non-induced cultures showed no oxidizing activity towards guanine, xanthine or uric acid even in cell-free extracts, and whole organisms oxidized these substrates only after a lag period during which the oxidizing enzymes were being synthesized. The inhibition of induction by chloramphenicol confirms the idea that the induction period involved the synthesis of new protein. Our experiments do not distinguish between the synthesis of the oxidizing enzymes alone and the synthesis of the oxidizing enzymes plus any permeases.

The experiments on the specificity of induction produced further confirmation of the proposed metabolic pathway. Cultures pre-induced with uric acid oxidized this compound rapidly but only metabolized xanthine and guanine after a lag of 30 to $60 \mathrm{~min}$. Those bacteria pre-induced by growth with xanthine or guanine, however, were capable of oxidizing all three substrates without lag. Since guanine deaminase is partly constitutive in these bacteria, these experiments could not be used to decide whether xanthine oxidase was induced only by xanthine or by both guanine and xanthine; but the uric acid oxidizing system was clearly induced by uric acid only and not by the other two purines. These enzymes appear therefore to follow a typical sequential induction path as first described by Stanier (1947).

The variation in the capacity of bacteria grown under different conditions to adapt to the oxidation of these purines suggests that the system may be subject to considerable repression by cell metabolites. Catabolite repression has been described for many systems but has been most intensively studied for Escherichia coli $\beta$-galactosidase (McFall \& Mandelstam, 1963; Nakada \& Magasanik, 1964; Loomis \& Magasanik, 1965). In the case of Pseudomonas aeruginosa it may be that induction of purine oxidizing enzymes is repressed by purine derivatives. Although 8-aza- 
guanine was a better substrate than guanine for the guanine-deaminating enzyme, it did not appear to act as an inducer for its synthesis and it was technically impossible to test whether it could prevent deaminase induction by guanine. There was no evidence of further metabolism of the azapurines beyond their deamination. This is supported by the fact that 8-azaguanine acted as a nitrogen source for growth but not as a carbon source.

The growth-inhibitory properties of 8 -azaguanine have been ascribed to its incorporation into RNA. Smith \& Matthews (1957) found that 100-500 $\mu \mathrm{M}$-8-azaguanine inhibited growth of Bacillus cereus and could replace $40 \%$ of the guanine in its RNA. Growth of Escherichia coli and tobacco mosaic virus was inhibited by 8-azaguanine at higher concentrations and there was less incorporation of the analogue into their RNAs. Growth of $B$. cereus was inhibited by $100-500 \mu \mathrm{M}-8$ azaxanthine, which was incorporated into its RNA, but it had no effect on the growth of $E$. coli or tobacco mosaic virus. It has since been reported that 8-azaguanine can replace guanine in transfer RNA, and in template or messenger RNA (Levin, 1965; Weinstein \& Grunberger, 1965). Rapid incorporation of 8-azaguanine into messenger RNA would be expected to give marked inhibition of the synthesis of enzymes being induced by exogenous inducers. But our earlier observations on permease induction suggested that the effect of 8-azaguanine on Pseudomonas aeruginosa was more complex. The experiments reported in the present paper confirm that this organism can deaminate 8-azaguanine at an appreciable rate and even use it as the sole nitrogen source for growth. The effect of 8 -azaguanine in inhibiting induction of xanthine oxidase and the uric acid oxidizing system was shown only when it was added before the inducer and at an equimolar concentration. This inhibition might have been due to the incorporation of 8-azaguanine into the specific messenger RNA molecules, but the greater sensitivity of xanthine oxidase as compared with the uric acid oxidizing system is more compatible with direct competition with the inducer. Several cases have been reported of inducer analogues which prevent induction by substrate or non-substrate inducers. For example, pheny]$\beta$-thiogalactoside prevents the induction of $\beta$-galactosidase in $E$. coli by methyl- $\beta$ $D$-thiogalactoside (Cohn \& Monod, 1953) and the amide analogue cyanoacetamide gives competitive repression of amidase induction by acetamide and $\mathrm{N}$-acetylacetamide in $\boldsymbol{P}$. aeruginosa (Clarke \& Brammar, 1964). The effect of 8-azaguanine and 8-azaxanthine on induction of the purine oxidizing enzymes might be due to competition with the purine substrates for inducer-binding sites. The relative differences observed in the effects of 8-azaguanine and 8-azaxanthine on the induction of xanthine oxidase as compared with the uric acid oxidizing enzymes would fit this interpretation.

Growth inhibition by 8 -azaguanine and 8-azaxanthine is unlikely to be related to any effect on induction of the purine-oxidizing system. The isolation of some mutants resistant to 8-azaguanine but not to 8-azaxanthine, while other mutants were resistant to both analogues, suggests that more than one site of attack may be involved. Altered permeability is unlikely to be the main factor in the increased resistance of the mutants to the analogues since both types of 8-azaguanine-resistant mutants showed the same 8-azaguanine inhibition of purine oxidation as did the parent strain. Furthermore, the high frequency of isolation of strains resistant to 8-azaguanine and 8-azaxanthine suggests that more than one type of mutation 
could confer resistance. Bergmann et al. (1964) found that their strain of Pseudomonas aeruginosa readily acquired resistance to 8-azaxanthine. One possible mechanism for this is suggested by the work of Gunther \& Prusoff (1963) who found that certain azathymine-resistant mutants of Streptococcus faecalis had decreased efficiency of thymine utilization and assimilated 6-azathymine less well than did the parent culture. More than one change in enzymes concerned with purine utilization could therefore produce cultures resistant to growth inhibition by 8-azaguanine and 8-azaxanthine.

The results of the growth experiments with Pseudomonas aeruginosa NCTC 8203, together with the results of the deamination and oxidation experiments, support the idea that the azapurines compete with the normal purines at several different metabolic sites. The marked deaminase activity of this strain towards 8-azaguanine confirms the view that the stimulation by 8 -azaguanine of oxygen uptake, with substrates such as succinate, can best be explained by the deamination of this compound which produces more ammonia for protein synthesis.

We are grateful to Mrs Renée Tata for excellent technical assistance.

\section{REFERENCES}

BACHRACH, U. (1957). The aerobic breakdown of uric acid by certain pseudomonads. J. gen. Microbiol. 17, 1.

Bergmann, F., Ungar-Waron, H. \& Kwietny-Govrin, H. (1964). Action of 8-azaguanine and 8-azaxanthine on Pseudomonas aeruginosa. Biochem. J. 91, 270.

Brammar, W. J. \& Clarke, P. H. (1964). Induction and repression of Pseudomonas aeruginosa amidase. J. gen. Microbiol. 37, 307.

Clarke, P. H. \& Brammar, W. J. (1964). Regulation of bacterial enzyme synthesis by induction and repression. Nature, Lond. 203, 1153.

Clarke, P. H. \& Meadow, P. M. (1959). Evidence for the occurrence of permeases for tricarboxylic acid cycle intermediates in Pseudomonas aeruginosa. J. gen. Microbiol. 20, 144.

CoHn, M. \& Monod, J. (1953). Specific inhibition and induction of enzyme biosynthesis Symp. Soc. gen. Microbiol. 3, 132.

Conway, E. J. (1957). Microdiffusion Analysis and Volumetric Error, 4th ed., p. 98. London: Crosby Lockwood and Son Ltd.

Creaser, E. H. (1956). The assimilation of amino acids by bacteria. 22. The effect of 8-azaguanine upon enzyme formation in Staphylococcus aureus. Biochem. J. 64, 539.

Dikstein, S., Bergmann, F. \& Henis, Y. (1957). Studies on uric acid and related compounds. IV. The specificity of bacterial xanthine oxidases. J. biol. Chem. 224, 67 .

Gunther, H. L. \& Prusoff, W. H. (1963). Studies on the mechanism of resistance to pyrimidines in Streptococcus faecalis. J. biol. Chem. 238, 1091.

LEVIN, D. H. (1965). Amino acid acceptor and transfer functions of s-RNA containing 8-azaguanine. Biochem. biophys. res. Commun. 19, 654.

Loomis, W. F. \& Magasanik, B. (1965). Genetic control of catabolite repression of the Lac operon in Escherichia coli. Biochem. biophys. res. Commun. 20, 230.

McFall, E. \& Mandelstam, J. (1963). Specific metabolic repression of three induced enzymes in Escherichia coli. Biochem. J. 89, 391.

MANDEL, H. G. \& MarkHaM, R. (1958). The effects of 8-azaguanine on the biosynthesis of ribonucleic acid in Bacillus cereus. Biochem. J. 69, 297.

Milner, H. W., Lawrence, N. S. \& French, C. S. (1950). Colloidal dispersion of chloroplast material. Science, 111, 633.

NAKada, D. \& Magasanik, B. (1964). The roles of inducer and catabolite repressor in the synthesis of $\beta$-galactosidase by Escherichia coli. J. mol. Biol. 8, 105. 
Roush, A. \& Norris, E. R. (1950). Deamination of 8-azaguanine by guanase. Arch. Biochem. 29, 124.

Smrth, J. D. \& Matthews, R. E. F. (1957). The metabolism of 8-azapurines. Biochem. J. 66, 323.

Stainer, R. Y. (1947). Simultaneous adaptation: A new technique for the study of metabolic pathways. J. Bact. 54, 339.

Weinstein, I. B. \& Grunberger, D. (1965). Coding properties of s-RNA containing 8-azaguanine. Biochem. biophys. res. Commun. 19, 647. 